\title{
Reflections on a Participatory Research Project: Young People of Refugee Background in an Arts-Based Program
}

\author{
Christopher C. Sonn, Michele Grossman, and Angela Utomo \\ Victoria University, Melbourne, Australia
}

\begin{abstract}
In Australia we have been engaged in community research with different groups who have been marginalised or excluded on the basis of race or ethnicity. To date, little research has been undertaken on the role of creative arts programs for refugee background young people. This article will describe a research project exploring how arts-based interventions facilitate well-being and settlement of recently arrived young people of refugee background. Specifically, the article discusses the usefulness of participatory research in evaluating a school-based arts program where refugee-background young people had the opportunity to tell their story through multiple media such as photos, individual narratives, and embodied performance (e.g., dance). Reflections and lessons on the challenges of conducting a participatory research project are also offered.
\end{abstract}

Keywords: Refugees, youth, arts, power, community-based research

\section{Introduction}

In this article we reflect on the success and challenges that developed in the context of research that sought to gain a better understanding of the role of arts programs delivered by The Song Room (TSR) in schools, and the role of TSR in promoting the wellbeing of young people who came to Australia under this nation's humanitarian refugee resettlement scheme. We were interested in the impacts and meanings of TSR programs for refugee background young people in relation to three overarching domains namely: sense of wellbeing, sense of belonging and social inclusion, and engagement with learning. These domains were contextualised in relation to the experience and demands of early phase settlement for these young people. 
The study was initially conceptualised using a quantitative quasi-experimental approach, in order to gather a robust evidence base for the role of arts in the settlement process. However, even though we understood the significance of developing 'objective scientific' evidence for the agency and funders, we were well aware of the range of methodological and political issues this raised, not least of which was its ability to capture and validate the experience and perceptions of the participants themselves. We were also aware of the need to promote refugee-focused research representing the voices of participants, which has received significant coverage in the research literature (e.g., Doná, 2007; Guerin \& Guerin, 2007). Accurate representation of voices is difficult to achieve with a research design in which the roles of key participants (i.e., young people) were limited to completing self-report measures. Accordingly, after considering the balance between what would be gained and what would be lost in applying the original methodology, we thus sought 'to trouble' (borrowing from Fine, 2012) the original design, the focus on measurement, and sought to move towards a more consultative, participatory and culturally attuned approach to research. We reframed the study so that it was guided by what has been articulated as Community Based Participatory Research (CBPR) and contextualism (Kingry-Westergaard \& Kelly, 2000). In this article, we provide a brief background to young refugee population in Australia, outline the evolution of a collaborative partnership with key stakeholders and participants of the study and identify the usefulness, challenges, and the lessons learned from conducting CBPR. Issues discussed include who is considered partners, epistemological questions related to creating different evidence, gathering data across difference, and using voices of participants to tell different stories.

\section{Refugee Background People in Schools}

Article 1 of the 1951 United Nations High Commissioner for Refugees Convention on the Status of Refugees defines a refugee as a 'person who is outside his/her country of nationality or habitual residence; has a well-founded fear of persecution because of his/her race, religion, nationality; membership in a particular social group or political opinion; and is unable to avail himself/herself of the protection of that country, or to return there, for fear of persecution' (UNHCR, 1951, 2007).

Across the world, there are approximately 1.6 million young refugees aged 12 to 17 years (UNHCR, 2009). Australia, with a long history of offering refugee status dating back to 1938 (Hanson-Easey \& Augoustinos, 2010), has made an annual estimate of 13,500 places (6500 for Refugees, 7000 for Special Humanitarian and Onshore Protection applicants) (Department of Immigration and Citizenship [DIAC], 2008). While many young refugees arrive in Australia with their immediate or extended family, others come as unaccompanied minors or with their siblings (O'Sullivan \& Olliff, 2006). The state of Victoria in the South Eastern part of Australia, resettles approximately one-third of Australia's humanitarian entrants each year and of these, more than $60 \%$ are aged 25 years or less (DIAC, 2007).

The terms 'refugee background young person' and 'refugee background young people' were used to refer to people aged between 10 and 18 years who share at least some common features of refugee experiences, regardless of their visa classification or status upon entry into Australia. 'Refugee experience/experiences' encompass the following: exposure to political, religious or intercultural violence, persecution or oppression, armed conflict or civil discord that incorporates the following basic elements: a state of fearfulness for self and family members, 
leaving the country of origin at short notice, inability to return to the country of origin, and uncertainty about the possibility of maintaining links with family and home (Coventry, Guerra, Mackenzie, \& Pinkney, 2002).

\section{The Song Room (TSR) and Arts in Schools}

TSR (2008) is a national not-for-profit organisation that provides learning opportunities to disadvantaged children through music and the creative arts. TSR offers weekly in-school workshop programs that include a range of creative and performing arts, which run for a minimum of six months and are complemented by other programs, including performances, holiday programs and professional development. The in-school workshops are tailored to meet the diverse needs of each school community, which may involve, for example, the formation of a choir or percussion group, classroom music programs, drama or creative movement programs.

Program planning is based on local need, demographics and 'evidence-based' exemplary practice. Support materials and activities, advice and professional development are provided to enhance the impact of the program and chances of its sustainability. Several best practice reviews around services and support for refugees and asylum seekers point to cultural participation as an important dimension of the social and psychological welfare of refugees and asylum seekers, and of the settlement process. The delivery of arts projects in both school and community contexts can create protective factors such as a strong sense of belonging and opportunities for personal expression and recognition of achievement. For example, Heath and Roach's (1998) ten-year study of youth arts organisations showed that young people engaged through creative 'experience and productivity' through playing many different roles, helping make rules, and through "taking inspiration through unexpected sources" (p. 22). Pope and Doyle (2006) reported that participants described a range of benefits including enjoyment, confidence and pride as well the development of new skills, networks and opportunities. In a study of four Australian school based art programs involving music and drama, Bryce (2004) found that involvement in arts programs had a positive impact on students' engagement with learning and, for Indigenous students at one school, led to improved attendance. In all four schools, the programs increased students' self-esteem; the contribution they made to the art project helped them feel more positive about themselves as learners. Similarly, Buys and Miller (2009) found that Community Cultural Development projects run in two socially disadvantaged Queensland schools significantly contributed to students' positive self- concept; "as a result of their involvement over two-thirds said that they feel better about themselves, had skills they could share with others and could do things as well as others" (Buys \& Miller, 2009, p. 10).

TSR has previously drawn on international research providing strong evidence that arts-based education improves children's learning and social development. For example, recent research in the United Kingdom into the impact of arts and culture on the integration of refugees and asylum seekers has found that the process of integration is closely linked to inclusion in social structures and developing strong relationships with others in the community (Gould, 2005). Creative Exchange is a UK based international network that specialises in public education on the role of arts and culture in addressing social change. In 2005, they produced a report on arts, culture and refugees (Gould 2005), the findings of which are based on an outline analysis of 76 projects and more detailed analysis of 33 projects. The report suggests that human 
relationships are integral to the process of feeling well settled and that refugees commonly feel integrated when they experience feeling safe from threats, welcomed, a sense of belonging and feeling part of the community and have friends. Gould (2005) also showed that culture and arts can play and important role in helping initiate and sustain relationships.

Given this background, a key aim of our study was to contribute direct evidence of the voices and views of young refugee background people themselves about their experience of participating in TSR programs, and especially how they felt TSR affected, enhanced or inhibited their sense of wellbeing, sense of belonging and engagement with learning. This was important because while TSR had a range of anecdotal evidence and feedback from teachers, principals and teaching artists about what children had to say of their involvement in TSR-led creative arts programs, no systematic collection or analysis of children's voices had previously been undertaken to confirm these perceptions. Also, there is a need to develop an evidence-based set of understandings of TSR impacts from the viewpoint of young people themselves that might inform changes or improvements to program delivery.

\section{Community-Based Participatory Research (CBPR)}

For this project, the research team comprised of eight researchers with both quantitative and qualitative research experience. Of those, four were trained in Community Psychology, two in Cultural Studies, and two in Education. Because consultation and partnership is important, we communicated that the methodology should be guided by community-based participatory research (CBPR) and a contextualist approach to knowing. CBPR is often interchangeably used with other terms such as community action research, participatory action research and community-based action research (Trickett \& Espino, 2004). Minkler and Wallerstein (2003) argue that CBPR is not a method or set of methods but is an approach to research. Minkler and Wallerstein describe it as "a process that involves community members or recipients of interventions in all phases of the research process" (p. 2). CBPR, like liberation-oriented methodologies (Montero, 2009), highlights participation as central to disrupting dynamics of oppression and exclusion and for promoting the voices of those the research is meant to benefit (Fisher, Sonn, \& Evans, 2007; Sonn \& Green, 2006). This disruption means attending to power, which is often expressed through symbolic means in research practices and processes, including issues to do with who conducts the research, what questions are asked, how groups are labelled, and what evidence is valued (Fine, 2012; Reyes Cruz \& Sonn, 2011; Teo, 2010). Reyes Cruz and Sonn (2011) have discussed the politics of research with marginalized communities and highlighted how research practices can be colonizing, while Teo (2010) used the notion of epistemological violence to "refer to specific theoretical interpretations of empirical results that have negative connotations for the Other in a given community" (p. 297). Thus, these issues are not solely related to the application of research findings but pertain to matters embedded in the framing of research and the broader social political context within which research is conducted.

In addition to promoting participation, we also articulated a contextualist approach to knowing, which emphasises that understanding behaviour requires us to attend to varied constructions of meanings in context and that people are embedded in social ecologies (Kingry-Westergard \& Kelly, 2000; Trickett \& Espino, 2004). With this orientation there is a focus on biographical methods and the voice of the key recipients of projects and interventions. 
Given that our project was informed by the principles of participation and promotion of young people's stories, we encouraged shared decision-making and mutual ownership of the research process and research outcomes with different stakeholders. For us, in practice, this meant creating opportunities for consultation and involvement of multiple actors. More specifically, the process of collaboration and reframing involved the following activities and articulation of guiding concepts:

- Involving and viewing school as community

- Interviewing students, teachers, principals

- Sharing resources with and acknowledging and appreciating skills and knowledge of school members at the different stages of research

- Consulting with participants, including educators and community members, regarding methods of data collection (surveys or interviews), procedures (logistics related to conducting the research), and how results should be disseminated and used for action

- Providing opportunities for the target participant groups to be involved in aspects of the research process

- Involving parents and community representatives through interviews.

Therefore, an initial first step in revising the research was to consult with key actors in schools. As part of the consultation process, the team sent the proposed draft survey instrument to schools for input about the suitability, appropriateness and accessibility of the two indices, the Personal Wellbeing Index and the Sense of Community Index. The team also undertook indepth consultation with five schools, conducting face-to-face interviews with four principals and six teachers. Through this consultation process and a review of literature, the research team was able to highlight that the quantitative design and instruments originally proposed, though sound in themselves, would be difficult to use with the target population in view of the language issues for early-phase refugees and the project's time (12 months), conceptual and linguistic equivalence of concepts, and resource parameters. The key challenges and concerns associated with the study as initially proposed, which emerged out of the scoping and consultation process, were methodological, epistemological and pragmatic concerns. These concerns were expressed by teachers and principals and were in line with the reservations held by the team. Principals and teachers raised their concerns about the suitability and appropriateness of administering repeated quantitative surveys. The key concerns of the teachers and researchers were that:

- Students, especially those who had not been in Australia for very long, would find some concepts in the survey difficult to understand, for example, 'this school helps me fulfill my needs'. Comprehension of concepts was a basic issue we had anticipated, but we were also concerned about the deeper level assumptions about the meanings of wellbeing and community that informed those questions (see also Birman \& Chan, 2008).

- Some questions were culturally inappropriate for some students, for example, one question related to money, and as pointed out by a principal and a teacher, Sudanese parents do not give money to their children. Again these questions assume cultural relevance and significance. 
- The surveys assumed students would possess a certain level of reflective thinking, which in reality was not the case, as they had experienced limited, interrupted prior schooling.

- Data would be skewed by students' willingness to please: students would want to make the teacher happy and answer very positively, especially refugee background young people who may fear the consequences of saying something negative.

- It would be difficult to recruit a large enough sample because of language and other procedural challenges related to parental consent. Relatively small sample sizes and brief follow-up periods were noted as major limitations to quantitative refugee research when attempting to capture change in refugees' experiences (Block, Warr, Gibbs, \& Riggs; 2012; Correa-Velez, Gifford \& Bice, 2005).

- To undertake a robust and culturally informed quantitative study, researchers would have required a longer timeframe and the opportunity to anchor the instruments in the meaning systems of the students prior to administration.

- English language school principals indicated that given the level of language comprehension of their students, the survey could not be implemented without interpreters. The benefit of employing translators or multicultural education aides is reported in Gifford, Bakopanos, Kaplan, and Correa-Velez's (2007) research on the psychosocial determinants of health and wellbeing among refugee background young people in Melbourne, Australia. However, due to unique challenges (limited comprehension of English, disrupted schooling, no prior exposure to or experience of research) the process of data gathering was extremely labor intensive and time consuming. Thus the cost and logistics of repeated quantitative measures was prohibitive.

- While employing translators would address the problem of language barriers, this process does not address the basic need to culturally anchor the instruments in the meaning systems of the young people. Thus through the consultation process we were able to develop additional information that helped with the case for a different approach. The project was thus revised to include in-depth case studies using multiple researchers and sources of data in six schools running TSR programs. Arguably, from our vantage point, through this process of consultation with different actors, our research was able to bring to the fore the often problematic assumptions about refugee background young people held by different stakeholders, including those representing the schooling system, and which informs practices with this population. Thus, the research process itself became a tool for promoting change in terms of meaning systems.

\section{Multiple Case Study Design: Promoting Voice and Maintaining Rigour}

Multiple-case study design (Yin, 2005) was used in the research in the six schools that were selected. These schools were selected on the basis that they ran TSR programs at the time of the study and had a large number of young people from culturally and linguistically diverse backgrounds who came to Australia as refugees. The schools included two primary English language schools, two secondary English Language schools, and one Catholic primary school and one primary school. In each of the schools the TSR program constituted the case for study. Across the six schools in different areas of metropolitan Melbourne, we interviewed a total of 55 (28 males and 27 females) children aged 10-18. Two schools had 12 participants, 
two had eight, and one had nine and six respectively. Participants were sampled purposively, based on their membership in one of the largest language groups of refugee background children in Victorian schools: Arabic, Dinka, Karen, Chin and Dari. These language groups corresponded with forced migrants from Sudan, Iran, Iraq, Burma and Afghanistan.

Multiple-case studies allowed us the opportunity for in-depth study of six sites and it also meant that we could explore what was unique and common across the different cases (Stake, 2008). Multiple cases also allowed us to develop insight about particular concepts in one setting but also the transferability of those insights to other settings. Zeicher and Liston (1996) noted that the transfer of concepts from case to case serve as a "heuristic in the form of analytical constructs of categories" (p.30) that can be used by others to reflect on their own practice. Furthermore, case studies require rich description, which in this case involved detailed observations by researchers of the actual cases as well as notes about research processes. These rich descriptions about the research processes and of the case study facilitate the transfer of insights and allow for the judgement of trustworthiness (Lincoln \& Guba, 1985).

Within the case study design we engaged multiple researchers where each research team member was responsible for one site. In order to ensure uniformity in research processes the chief investigators of the project (i.e., first and second author) developed a case study protocol for data gathering, management and analysis, consistent with the recommendations' of researchers (see Yin, 2009). The protocol was made up of semi-structured interview schedules to be used for interviewing teaching artists, teachers, students and some parents and observation schedules to ensure that researchers described similar features of the teaching space. We chose semi structured interviewing to ensure that similar topics were explored across case study settings. The protocol also included a guide for coding the transcribed interviews and for how to enter responses into a question-ordered matrix that was set up as an excel spreadsheet. The protocol helped to ensure the uniformity in data gathering at the different schools and it enhanced the rigour of our study (Miles \& Huberman, 1994). The protocol served as a key document of communication for the team and was discussed at the different workshops that involved the entire research team.

Throughout the entire project, three two-hour workshops were conducted. The first two workshops were conducted prior to data gathering to share methods of data collection and develop specific interview, observation, and focus group schedules as well as sharing the specific processes or the protocol. After data gathering, another workshop was conducted to debrief and to share insights about the research and data gathering process. The debriefing session also provided and opportunity for the group to begin discussion on themes emerging within and across case settings and identifying key lessons learnt (see Crawford, Leybourne, \& Arnott, 2000). This stage in the process is in line with Miles and Huberman's (1994) group interim data analysis -- it is part of the iterative approach to data management.

Multiple researchers' enabled us to explore the issues from multiple perspectives. Moreover, our study used field notes, observations, and interviews with different participants, which made data and researcher triangulation possible. Within each of the case studies, classroom teachers, school principals, TSR teaching artists, parents of participating children and community leaders from relevant communities were interviewed individually or in a group in one case when there were two or more teaching artists in a school. Individual semi-structured interviews were chosen because we believed that the one-on-one conversational format would help us delve 
deeply into each individual's experiences of TSR and would allow the interviewee to feel that they could open up without being interrupted by others or restricted with a fixed agenda. This method also reflected a more participatory approach to research where researchers' superiority of knowledge was not assumed (Small, 1995). The primary data was collected from the young people in different schools using face-to-face interviews, which were facilitated by an accredited translator.

In order to promote the participation of the young people, a few weeks prior to the interviews they were involved in a photo-elicitation activity. Derived from participatory research approaches, photo-elicitation method was utilised to assist in addressing the power imbalance between the researcher and children participants, ensuring that the study was conducted with, not on, children (Clark, 2010). Purcell (2007) suggested that photo-elicitation was an empowering form of individual and community development and highlighted the use of photographs to trigger discussion. In the case of our research, the students were encouraged to take photographs and to select pictures that they would in turn write about in terms of what it means to them. The photo-elicitation process was a means to engage the young people and was welcomed by schools. This aspect of the project was designed as a whole-of-class exercise. Following a briefing for the teachers, who facilitated this activity, students were provided with a disposable camera with 27 photographs exposures and invited to take pictures of people, objects, symbols that they felt represented their involvement in TSR program and their school. The following four prompts were used: a) Something that is special to you about your school; b) Something that is special to you about TSR class; c) Something that makes you feel good about yourself; d) Something you want to learn more about. After photos were developed, in a class activity students were asked to select images to be included in their journals and write a brief description under each photo to contextualise it. The photo journals represented the objective expression of the meanings of participation and for the researchers it was a key tool to engage the young people in the interview process. For the young people, the photoelicitation activity meant being able to capture aspects of their social worlds, engage in an activity that was fun and creative, enforce reading and writing skills, and reflect on the meanings of participating in everyday activities at school.

\section{Findings}

Our analysis of data collected for the different case studies provided support for the role of arts in promoting wellbeing. Importantly, we followed a contextualist framework that highlighted the centrality of meanings for the different participants. To this end we conceptualised the TSR program as an event or activity setting within a broader social ecology including the everyday stories and discourses about asylum seekers and refugees in Australia. Given this, it was clear that TSR programs can be viewed as specific settings within a broader schooling program that offers students the opportunity for active engagement in arts-based activities. This opportunity for participation in arts activities means different things for different students and have specific learning, social and cultural dimensions that are reflected in some of the different outcomes the students' reported in the interview data in the different case studies.

The themes that we identified following analysis of the interview data gathered from the young people in the different case studies related to dimensions of engagement with learning, engaging with significant others, and intercultural exchange, which are summarised in Table 1. 
Table 1

TSR and Opportunities for Personal and Social Development

\begin{tabular}{|c|c|c|c|}
\hline Theme & Category & $\begin{array}{l}\text { Reported by } \\
\text { Participants at } \\
\text { Participating School }\end{array}$ & Illustrative Quotations \\
\hline \multirow[t]{3}{*}{$\begin{array}{l}\text { Engagement } \\
\text { with } \\
\text { Learning }\end{array}$} & $\begin{aligned} & \text { Learning language } \\
& \text { • } \text { Songs } \\
& \bullet \text { Expression } \\
& \bullet \text { Pronunciation }\end{aligned}$ & 6 out of 6 schools & $\begin{array}{l}\text { - I would say it's fun to be in drama class. } \\
\text { You be comfortable and take your time to } \\
\text { learn English and I know you will enjoy } \\
\text { yourself. } \\
\text { Helped me because I don't know the } \\
\text { name of animal in English you cannot get } \\
\text { anywhere else. }\end{array}$ \\
\hline & $\begin{aligned} & \text { Learning arts/skills } \\
& \text { - } \text { Musical instrument } \\
& \text { - } \text { Singing } \\
& \text { - } \text { Dance ('new } \\
& \text { moves') } \\
& \text { - } \text { Performance }\end{aligned}$ & $\begin{array}{l}6 \text { out of } 6 \text { schools } \\
\text { All participants } \\
\text { mention learning a } \\
\text { skill. }\end{array}$ & $\begin{array}{l}\text { - I like it because it feels like the movement } \\
\text { and dancing. } \\
\text { - I learnt different types of drumming } \\
\text { - You have to shake your body...like PE you } \\
\text { have to move your body parts. } \\
\text { - Really want to get it, I also want to get } \\
\text { other movements that [named teaching } \\
\text { artist] has in her. I want to learn more } \\
\text { about jazz, like not just those other } \\
\text { movements we perform, but different } \\
\text { things. }\end{array}$ \\
\hline & $\begin{array}{cl}\text { Personal development } \\
\text { - } & \text { Aspirations } \\
\text { - } & \text { Enthusiasm and } \\
& \text { energy to engage } \\
\text { - } & \text { Future identities } \\
& \text { and roles } \\
\text { - } & \text { Confidence }\end{array}$ & 5 out of 6 schools & $\begin{array}{l}\text { We play Kye Kye Kule [African's rhythmic } \\
\text { head and shoulders game] and next week } \\
\text { we're going to teach other school to - at } \\
\text { the art gallery, learn to teach the other } \\
\text { school, like playing that and we are the } \\
\text { leader...At music, art class - not art class, } \\
\text { music class, I don't be shy. I feel } \\
\text { confidence...I feel like - I don't know. } \\
\text { Because it just came to me, confidence... } \\
\text { [in the] Second [class]. } \\
\text { I feel good.. That I've learned how to play } \\
\text { something that I've never ever seen...I } \\
\text { feel that I'm a quick learner, instruments } \\
\text { and stuff, pretty much. }\end{array}$ \\
\hline \multirow[t]{2}{*}{$\begin{array}{l}\text { Social } \\
\text { relations }\end{array}$} & Forming friendships & 6 out of 6 schools & $\begin{array}{l}\text { - Coordination with the other friends, when } \\
\text { we do the acting together. } \\
\text { It's a drumming class, so the way we work } \\
\text { together and the boys, we work together } \\
\text { and we not want to make mistakes. We } \\
\text { beat the drum. If someone makes a } \\
\text { mistake it's difficult to continue. }\end{array}$ \\
\hline & Relating to teachers & 3 out of 6 schools & $\begin{array}{l}\text { - } \quad \text { My classroom teacher] is very good } \\
\text { singer..... Every time when it is coming } \\
\text { from the inside. She sings from the inside. } \\
\text { - This teacher is very fun...and like smiling... } \\
\text { - The most important thing and special } \\
\text { thing for me about drama is that students } \\
\text { are sitting next to each other and work } \\
\text { together on what their teacher said. }\end{array}$ \\
\hline
\end{tabular}


We provide some examples of the participants' comments taken from the larger body of data to illustrate the broader themes that we constructed to address the key research questions. These themes capture the comments made by most of the participants in each of the case studies, and are summarised in Table 1. In addition, although photo-elicitation was utilised to foster the research relationship and to provide students with an opportunity to discuss aspects of their life worlds (Loeffler, 2004), the photo elicitation data also revealed similar themes. For instance, comments made about photographs of 'social situations' and people engaging in activities were consistent with the theme of 'Social relations'.

Engaging with learning captures the personal and social developmental outcomes such as learning to play an instrument, developing vocabulary, learning how to express English language words, social roles and accomplishing tasks. For example, a participant at a primary ESL school reported that: "When I am in The Song Room, when you are singing a song, how to get the tone out in your voice and how to sing from the inside and sing properly, not singing silly - that's what's important". Another commented: "I like something in the music class, it is like you get to learn about music and instruments and stuff because you never know, or how do you do things. Like how do you play ukulele...you get to learn it at school, not at home or somewhere else. At school and it's fun". A participant at a secondary ESL School reported: "I would say it's fun to be in drama class. You be comfortable and take your time to learn English and I know you will enjoy yourself".

Engaging with significant others reflects the role of friends and of teachers in experiencing a sense of belonging and safety in school contexts. In particular these findings show how important friends are to the young people as well as the significant role of teachers as forms of support and as role models. A participant noted: "I really want to get it. I also want to get other movements that [teaching artist] has in her. I want to learn more about jazz, like not just those other movements we perform, but different things". Participants typically commented about being together with friends. For example: I like this photo because everyone's faces look like funny the smile and...I put this picture because everybody smiling and singing to my favourite music...I like this photo because my friends are all together and the faces look like fun. (Primary ESL) Another reported that: My friend Arif told me that you have to learn this, and he kept telling me how to do it until I learnt how to do it [and] I learn from Callie the things that she was telling us...When she tells something and I don't understand, he comes and tells me. Another commented: "The most important thing and special thing for me about drama is that students are sitting next to each other and work together on what their teacher said (ELS Secondary)".

The intercultural dimension reflected transculturation, that is, the opportunity of sharing and rearticulation of prior learning into the new context. Importantly, the voices of the young people provided a complex and nuanced picture of the ways in which the young people show agency in constructing their everyday lives at school and in TSR programs. These were reflected in the following comment: "I like to play drums at school...dancing and playing the drum. Yeah, because in our Kareni [Burma] area, every time we celebrate we play, this is part of the tradition, the drum, and we dance." Another reported that: "I will show my mum the dance we learn [in TSR class], I tell her about it, she says 'good' and then she says, 'Why can't we use a bit of that dance with our own dance'." 
The participants' comments show the significance of supportive social environments as they construct their lives. For us this reaffirmed the importance of highlighting the stories the students were telling about their lives at school and outside and the centrality of these settings for negotiating everyday settling as counter stories to the hegemonic media narratives about damaged refugees.

\section{Embodied research practice}

The research design we used also pointed to the significance of CBPR for allowing insights to develop through alertness to the embodied nature of contextualised research in ways that move beyond merely hearing the voices of participants. Different art forms and genres including instrumental music, dance, singing and visual arts were being practiced across the six case study sites during the research. In the case of participants who were involved in dance classes through TSR, the participant-observer and interview methods used as part of the case study approach allowed the research team to develop analysis and insights using embodied performance-based data - both spontaneous and formal - that would have been completely unavailable in the original study design. Some young participants, for example, chose to spontaneously perform the 'new moves' they were learning in TSR dance classes for the researchers as a way of expressing the meaning of particular art forms in relation to engagement and wellbeing, in effect, demonstrating engagement with learning through their own embodied practice.

Moreover, observing performance-based class interactions between participants and between participants and the TSR teaching artists offered new insights around how embodiment can be used to convey specific cultural meanings as well as facilitate cross-cultural understanding and engagement. The embodied presence of the researchers themselves as part of the case study approach meant that participants were able to relate their experience of TSR programs in a setting that permitted not merely 'reporting' or 'telling' but physically demonstrating the meaning and impact of aspects of their learning and wellbeing through arts-based teaching. This enhanced understanding of the kinds of existing social capital held by a number of participants that would have remained obscured in a more traditionally focused mode of research inquiry.

\section{Discussion}

For us there were multiple lessons, challenges, and insights related to conducting research with people who have refugee experiences, especially those early in their settlement, who are now living in Australia. We described the process and will highlight some of these that were pertinent. From the outset of the research process we had to negotiate dominant understandings of evidence, the needs of TSR, along with the need to include the voices of the young people. Voutira and Doná (2007) have discussed the tensions that arise between advocacy and scholarship. In this work, the funding agency needed evidence to help with promoting its own agenda of the relevance and importance of this mode of learning in an education system that does not formally fund these programs in schools. Evidence for the review was seemingly based on the collection of objective data that could illustrate that the programs impacted directly upon the wellbeing of learning of young people. For us this was limiting and problematic because this type of research often meant stripping away some of the 
context of inquiry and of everyday life and thereby failing to recognise the complexity and diversity of participants lives. We advocated for a participatory methodology informed by a contextualist approach to knowing (Kingry-Westergard \& Kelly, 2000). Such an approach would allow us to reframe evidence and find ways through photo-elicitation and translator assisted interviews to include the voices we were most interested in hearing from. This is a balancing act, but also a political act of engaging with the political and ethical dimensions of research (see, Block et al., 2012). Ultimately we want to promote research that is ethical, rigorous and credible and that can impact positively on policies and programs in communities and for communities settling in new contexts (see also Doná, 2007; Fine, 2012;Voutira \& Doná, 2007).

Our emphasis on a contextualist approach to knowing meant favouring stories. Given this we, needed to find ways to open channels and means for communicating across cultural and linguistic differences as well as with different actors. In terms of the primary participants, communication was enabled by the employment of translators who also had cultural knowledge that could foster understanding of some of the cultural frames used by the young people to understand their experiences. It also meant that we could bring the voices of young people more centrally into the overall process and intended research outcomes. After all, these young people are meant to be the key beneficiaries of the programs and the research. We avoided constructing an external community, and instead emphasised consulting across agencies and significant others and with the target group in order to include multiple voices (through photo elicitation, journal writing, and participant observation). This meant that we ended up with a complex data set with multiple voices that had to be included in the final report. At a different level, by collaborating and expanding the network of actors (official and unofficial, see Doná, 2007) we were also able to at least consult and foster a shared investment across agencies in the research thereby broadening the field for whom this research will be meaningful and relevant.

Although the funding agencies' agendas took priority, our own experiences of researching with diverse groups and the ways in which academic research is often complicit in colonising practices (Reyes Cruz \& Sonn, 2011) or epistemological violence as Teo (2010) frames it, meant that we opened up opportunities to begin to challenge dominant understandings of refugeebackground young people's experiences with the voices of the young people. We were careful to avoid constructing the 'refugee communities' as a research object, which is so often the case in community research partnering those who are marginalised. This is a problematic signifying practice, which results in homogenising and stigmatising people who are forced migrants. For example, the voices of the young people in the research offer a stark contrast to the story of trauma that pervades official stories and therefore official programs. Importantly, this was the first time that data was gathered for the agency that included the voices of the students, which in our view was a significant step.

In summary, drawing on the principles of CBPR and contextualist approaches allowed us to open up processes for inclusion, reframing, and doing research differently. While we were still constrained by funding agreements and narrow understandings of evidence, we were able to shift the research so that we could highlight the ways in which young people are actively engaged in settling and constructing their lives in everyday settings. We were able to disrupt the institutional and governing practices of constructing and fixing 'refugee identities' and that predominantly highlight 'trauma' (see Doná, 2007; Westoby \& Ingamells, 2010). While this may 
be one part of the experience, the young people tell other stories about constructing lives in everyday settings. The young people highlight positive experiences that counter the professional discourse that can undermine settling practices. We would argue that through the processes of consultation and bringing together diverse actors voices with those of the young people, the research was able to influence how service providers and educators conceive of the young people, their needs, and the agentic ways in which the young people go about constructing lives within supportive and enabling schooling environments. For us, critically reflecting on and reconstructing research processes and practices in order to promote change towards social justice remains an extremely important project within globalising and increasingly diverse contexts.

Note: This article is based on research conducted with funding support from the Macquarie Foundation for The Song Room. The full report details are: Grossman, M. \& Sonn, C. C. (2010). New Moves: Understanding the Impact of The Song Room Programs for Young People from Refugee Backgrounds. Melbourne, Australia: The Song Room. A version of this article was presented at the 30th International Congress of Psychology held in Cape Town, South Africa, 22-27 July 2012.

Contact information:

Christopher C. Sonn

College of Arts

Victoria University

FP Campus, PO Box 14428, Melbourne City, 8001

Email: Christopher.sonn@vu.edu.au

\section{References}

Birman, D. \& Chan, W. (2008, May).Screening and assessing immigrant and refugee youth in school based mental health programs. Issue Brief \#1, Center for Health and Health Care in Schools, George Washington University. Retrieved from http://www.rwjf.org/files/research/3320.32211.0508issuebriefno.1.pdf

Block, K., Warr, D., Gibbs, L., \& Riggs, E. (2012). Addressing ethical and methodological challenges in research with refugee-background young people: Reflections from the field. Journal of Refugee Studies, 26(1), 69-87. Doi:10.1093/jrs/fes002

Bond, L., Thomas, L., Toumbourou, J., Patton, G. \& Catalano, R. (2000). Improving the lives of young Victorians in our community: A survey of risk and protective factors. Melbourne: Centre for Adolescent Health. 
Bryce, J. (2004). Evaluation of school-based arts education programs in Australian schools. Research Developments, 12(4), 13-15. Retrieved from http://research.acer.edu.au/resdev/vol12/iss12/4

Clark, A. (2010). Young children as protagonists and the role of participatory, visual methods in engaging multiple perspectives. American Journal of Community Psychology, 46, 115123.

Correa-Velez, I., Gifford, S.M., \& Bice, S.J. (2005). Australian health policy on access to medical care for refugees and asylum seekers. Australia and New Zealand Health Policy, 2(23), Retrieved from http://www.anzhealthpolicy.com/content/2/1/23

Coventry, L., Guerra, C., Mackenzie, D., \& Pinkney, S. (2002). Wealth of all nations: Identification of strategies to assist refugee young people in transition to independence. Hobart, Tasmania: Australian Clearinghouse for Youth Studies.

Crawford, K. H., Leybourne, M. L., \& Arnott, A. (2000). How we ensured rigour in a multi-site, multi-discipline, multi-researcher study. Forum: Qualitative Social Research, 1(1), Art. 12. Retrieved from http://www.qualitative-research.net/fqs-texte/1-00/1-00crawfordetale.htm.

Doná, G. (2007). The microphysics of participation in refugee research. Journal of Refugee Studies, 20(2), 210-229.

Department of Immigration and Citizenship. (2007). Migrating as a refugee or humanitarian entrant. Retrieved from http://www.immi.gov.au/refugee/index.htm

Department of Immigration and Citizenship. (2008). New beginnings: Supporting new arrivals on their settlement journey 2006-07. Retrieved from www.immi.gov.au/media/publications/settle/_.../new_beginnings.pdf

Fine, M. (2012). Troubling calls for evidence: A critical race, class and gender analysis of whose evidence counts. Feminism and Psychology, 22(3), 3-19.

Fisher, A. T., Sonn, C. C., \& Evans, S. D. (2007). The place and function of power in community psychology: Philosophical and practical issues. Journal of Community and Applied Social Psychology, 17, 258-267.

Gifford S. M., Correa-Velez, I., \& Sampson, R. (2009). Good Starts for recently arrived youth with refugee backgrounds: Promoting wellbeing in the first three years of settlement in Melbourne, Australia. Melbourne, Australia: La Trobe Refugee Research Centre, La Trobe University.

Gifford, S., Bakopanos, C., Kaplan, I., \& Correa-Velez, I. (2007). Meaning or measurement? Researching the social contexts of health and settlement among newly- arrived refugee youth in Melbourne, Australia. Journal of Refugee Studies, 20, 414-440. 
Guerin, P., \& Guerin, B. (2007). Research with refugee communities: Going round in circles with methodology. The Australian Community Psychologist, 19, 150-162.

Grossman, M. \& Sonn, C. C. (2010). New moves: understanding the impacts of The Song Room programs for young people from refugee backgrounds. Melbourne, Australia: The Song Room.

Hage, G. (1998). White nation: Fantasies of white supremacy in a multicultural society. Sydney, Australia: Pluto Press.

Hanson-Easey, S., \& Augoustinos, M. (2010). Out of Africa: Accounting for refugee policy and the language of causal attribution. Discourse \& Society, 21(3), 295 - 323.

Harper, D. (2002). Talking about pictures: a case for photo elicitation. Visual Methods, 17, 1326.

Kingry-Westergaard, C. \& Kelly, J. G. (2000). A contextualist epistemology for ecological research. In P. Tolan, P., C. Keys, F. Chertok, \& L. Jason. (Eds.). Researching community psychology: Issues of theory and methods (pp.23-31) Washington, DC: APA.

Lau, A.L.D., Cummins, R.A. and McPherson, W. (2004). An investigation into the cross-cultural equivalence of the Personal Wellbeing Index. Social Indicators Research, 72, 403-432.

Loeffler, T. A. (2004). A photo elicitation study of the meanings of outdoor adventure experiences. Journal of Leisure Research, 36(4), 536-556.

Miles, M. B., \& Huberman, A. M. (1994). Qualitative data analysis: An expanded source-book (2nd ed.). Thousand Oaks, CA: Sage.

Minkler M., \& Wallerstein, N. (2003). Community based participatory research for health: From process to outcomes. San Francisco, CA: Jossey-Bass Publishers.

Montero, M. (2009). Methods for liberation: Critical consciousness in action. In M.Montero \& C.C. Sonn (Eds.), Psychology of liberation (pp. 73-91). New York, NY: Springer. doi: 10.1007/978-0-387-85784-8_4

O'Sullivan, K., \& Olliff, L. (2006). Settling in: Exploring good settlement for refugee young people in Australia. Melbourne, Australia: Melbourne Centre for Multicultural Youth Issues.

Peterson, N. A., Speer, P. W., \& McMillan, D. W. (2008). Validation of a brief sense of community scale: Confirmation of the principal theory of sense of community. Journal of Community Psychology, 36, 61-73.

Purcell, R. (2007). Images for change: community development, community arts and photography. Community Development Journal, 44, 111-122. 
Reyes Cruz, M. \& Sonn. C. C. (2011). (De)colonizing culture in community psychology: Reflections from critical social science. American Journal of Community Psychology, 47, 203-2014.

Small, S.A.(1995). Action oriented research: Models and methods. Journal of Marriage and Family, 57(4), 941-955

Stake, R. E. (2008). The art of case study research. Thousand Oaks, CA: Sage Publications.

Sonn, C. C., \& Fisher, A. T. (2010). Immigration and settlement: Confronting the challenges of cultural diversity. In G. Nelson \& I. Prilleltensky (Eds.) Community psychology: In pursuit of liberation and well-being (2nd ed) (pp. 371-388). London: Palgrave.

Sonn, C. C., \& Green, M. J. (2006). Disrupting the dynamics of oppression in intercultural research and practice. Journal of Community and Applied Social Psychology, 16 (5), 337346.

Trickett, E. J., \& Espino, S. L. (2004). Collaboration and social inquiry: Multiple meanings of a construct and its role in creating useful and valid knowledge. American Journal of Community Psychology, 34(1/2), 1-69.

Teo, T. (2010). What is epistemological violence in the social sciences? Social and Personality Psychology Compass, 4/5, 295-303.

The Song Room. (2008). The song room post program evaluation data. Retrieved June 24, 2010, from http://www.songroom.org.au/images/stories/research/Post_Program_Evaluation_Summ ary_for_Website_S12010.pdf

United Nations High Commissioner for Refugees. (1951, July). United Nations convention relating to the status of refugees. Retrieved from http://www.unhcr.org/refworld/pdfid/44201a574.pdf

United Nations High Commissioner for Refugees. (2005). Protecting refugees: New resettlement programmes. Geneva, Switzerland: Author.

Voutira, E. \& Dona, G. (2007). Refugee research methodologies: Consolidation and transformation of a field. Journal of Refugee Studies, 20(2), 163-171.

Westoby, P., \& Ingamells, A. (2010). A critically informed perspective of working with resettling refugee groups in Australia. British Journal of Social Work, 40, 1759-1776.

Yin, R., K. (2009). Case study research: Design and methods. Thousand Oaks, CA: Sage Publications.

Zeichner, K. M., \& Liston, D. P. (1996). Reflective teaching: An introduction. Mahwah, NJ: Erlbaum 